\title{
University of Nebraska unmanned aerial system (UAS) profiling during the LAPSE-RATE field campaign
}

\author{
Ashraful Islam ${ }^{1}$, Ajay Shankar ${ }^{1}$, Adam Houston ${ }^{2}$, and Carrick Detweiler ${ }^{1}$ \\ ${ }^{1}$ NIMBUS Lab, Department of Computer Science and Engineering, \\ University of Nebraska-Lincoln, Lincoln, NE 68588, USA \\ ${ }^{2}$ Department of Earth and Atmospheric Sciences, University of Nebraska-Lincoln, Lincoln, NE 68588, USA
}

Correspondence: Ashraful Islam (mislam@ @uskers.unl.edu)

Received: 4 December 2020 - Discussion started: 17 December 2020

Revised: 30 April 2021 - Accepted: 5 May 2021 - Published: 2 June 2021

\begin{abstract}
This paper describes the data collected by the University of Nebraska-Lincoln (UNL) as part of the field deployments during the Lower Atmospheric Process Studies at Elevation - a Remotely-piloted Aircraft Team Experiment (LAPSE-RATE) flight campaign in July 2018. The UNL deployed two multirotor unmanned aerial systems (UASs) at multiple sites in the San Luis Valley (Colorado, USA) for data collection to support three science missions: convection initiation, boundary layer transition, and cold air drainage flow. We conducted 172 flights resulting in over $21 \mathrm{~h}$ of cumulative flight time. Our novel design for the sensor housing onboard the UAS was employed in these flights to meet the aspiration and shielding requirements of the temperature and humidity sensors and to separate them from the mixed turbulent airflow from the propellers. Data presented in this paper include timestamped temperature and humidity data collected from the sensors, along with the three-dimensional position and velocity of the UAS. Data are quality-controlled and time-synchronized using a zero-order-hold interpolation without additional post-processing. The full dataset is also made available for download at https://doi.org/10.5281/zenodo.4306086 (Islam et al., 2020).
\end{abstract}

\section{Introduction}

A team of researchers from the University of NebraskaLincoln (UNL) participated in the Lower Atmospheric Process Studies at Elevation - a Remotely-piloted Aircraft Team Experiment (LAPSE-RATE) flight campaign between 1419 July 2018 at San Luis Valley of Colorado, USA. LAPSERATE was organized as part of the International Society for Atmospheric Research using Remotely-piloted Aircraft (ISARRA) 2018 meeting. A total of 1287 flights were conducted by 13 institutions, including the UNL, which resulted in more than $260 \mathrm{~h}$ of data collection. The UNL's contribution to this collaborative data collection effort was 172 atmospheric boundary layer (ABL) profiling flights using two multirotor unmanned aerial system (UAS) platforms. These flights from the UNL resulted in over $21 \mathrm{~h}$ of data being collected. This unique collaboration resulted in a collective sampling of a variety of atmospheric phenomena over the span of $6 \mathrm{~d}$ at preplanned sites around the San Luis Valley. An overview of the LAPSE-RATE campaign, the description of site locations, and science missions that focused on measuring different atmospheric phenomena of interest are documented (de Boer et al., 2020a, b). Data from the UNL and all other participating teams in the LAPSE-RATE campaign are hosted in an open-access data repository (LAPSE-RATE Data Repository, 2021).

Multirotor UASs are finding more routine uses for sampling and profiling the ABL, such as atmospheric profiling (Bonin et al., 2013; Elston et al., 2015; Greatwood et al., 2017; Jacob et al., 2018; Islam et al., 2019; Barbieri et al., 2019; Segales et al., 2020), estimation of the spatial structure of temperature (Hemingway et al., 2020), wind measurement (Prudden et al., 2016; Palomaki et al., 2017), and prediction of Lagrangian coherent structure (Nolan et al., 2018).

The need for increased spatial resolution for atmospheric sampling is reflected in publications, such as improving 
numerical weather prediction (NWP) models (Leuenberger et al., 2020), improvement of mesoscale atmospheric forecast (Dabberdt et al., 2005), and identification of hazardous weather for beyond visual line of sight (BVLOS) flights using UAS traffic management (UTM) systems (Mitchell et al., 2020). UASs can meet such profiling needs with a greater frequency of profiles, increased spatiotemporal resolution of data, and sampling in virtually any sampling location when compared with traditional methods. Multirotors extend the sampling capability by allowing rapid and repeatable profiling at any site while maintaining a fixed horizontal position.

Our previous work (Islam et al., 2019) describes the design and evaluation of a temperature and humidity $(\mathrm{TH})$ sensor housing that meets the recommended sensor placement, aspiration, and shielding criteria by using a passively inducedairflow technique that works by exploiting the existing UAS propeller. The housing's inlet is pointed outwards from the UAS to sample just outside of the UAS turbulence in both ascent and descent. This is different from existing methods of placing the sensor under the arm without shielding but aspirated by the propeller (Hemingway et al., 2017), on the body of the UAS without shielding and aspiration (Lee et al., 2018), or on a different part of the UAS with shielding and possible aspiration from propellers (Greene et al., 2018) or shielding the sensor inside the UAS and with active aspiration using a fan while pointing the inlet towards the wind (Greene et al., 2019). All of these existing configurations fail to produce reliable data during descent, and these data are usually discarded (Lee et al., 2018). As multirotor flight time is very limited, needing to discard the entire descent data prevents optimal use of resources. Additionally, in most cases, observations are affected by wind direction and require onboard sensing of wind and reorientation of the UAS with the change in wind direction (Greene et al., 2019).

Two primary highlights of our novel sensor housing are its ability to obtain temperature and humidity sensor readings reliably during both ascent and descent profiles and its invariance to the aircraft orientation relative to the ambient wind. Two key design considerations in achieving these goals are the placement of the sensor and its consistent aspiration. Placement of the sensor on the UAS body can adversely affect the measurements (Greene et al., 2018; Jacob et al., 2018). As observed through prior experimental results (Villa et al., 2016), the accuracy of a sensor's measurement increases the farther away it is placed from the propeller's downwash. More specifically, a sensor placed at a distance at least 2.5 times the propeller diameter away from the rotor experiences significantly less aerodynamic interference (Prudden et al., 2016). Consistent and sufficient aspiration is also necessary for a consistent effective sensor response time (Houston and Keeler, 2018). Placing the sensor inside the propeller region or near the body can result in inconsistent aspiration due to rotor turbulence (Diaz and Yoon, 2018; Yoon et al., 2017). As such, we designed our sensor housing to source the sampling air from outside rotor inter- ference and to maintain consistently high aspiration airspeed to obtain reliable results.

Our sensor housing design has evolved over multiple design iterations and has been field-tested in multiple Collaboration Leading Operational UAS Development for Meteorology and Atmospheric Physics (CLOUD-MAP) field campaigns (Jacob et al., 2018). The details of our data validation tests as well as a complete description of the sensor housing design are available in a separate open-access paper (Islam et al., 2019).

For the LAPSE-RATE campaign, the UNL deployed two identical UASs with one primary-sensor suite for measurements and a secondary-sensor suite for redundancy and testing. These flights were conducted at five locations in San Luis Valley (Colorado, USA) through 14-19 July 2018. The maximum altitude for each flight ranged from 100-500 m above ground level. Figure 1 illustrates the UAS with the housing setup, a closeup of the sensor housing, and sensor mounting configurations. Both primary and secondary sensors are located inside their respective sensor housings mounted on two diametrically opposing arms of the UAS. In some flights, a third sensor was mounted under the body frame of the UAS to compare the performance of primary sensors against traditional mounting positions. A detailed description of our configuration is presented in Sect. 2.5. It should be noted that, although the data collection is focused on the temperature and humidity measurements, atmospheric pressure data from the sensors are also included in the dataset for anyone interested.

The rest of the paper describes the components of our system (Sect. 2), the flight strategies employed for missions (Sect. 3), the data processing used (Sect. 4), and some special topics of interest (Sect. 5). We finally conclude with example profile data and provide details regarding the availability of the dataset.

\section{System description}

\subsection{UAS platform}

The two identical UASs deployed during the missions were developed on a DJI Matrice 600Pro platform equipped with DJI A3 Pro flight control systems. The unfolded dimensions (including propellers, frame arms, GPS mounts, and landing gear) of the system are $1668 \mathrm{~mm} \times 1518 \mathrm{~mm} \times 727 \mathrm{~mm}$. The recommended maximum payload capacity of the platform is $5.5 \mathrm{~kg}$. At no load, the UAS has a flight endurance of 35-40 min on a single set of six DJI TB48S batteries. The manufacturer-specified positioning accuracy is $\pm 0.5 \mathrm{~m}$ in the vertical axis and $\pm 1.5 \mathrm{~m}$ horizontally (DJI, 2021b). The maximum ascent and descent speeds are 5 and $3 \mathrm{~m} \mathrm{~s}^{-1}$, respectively. The flight controller offers real-time access (readonly) to the UAS's onboard sensor data, such as position, velocity, and attitude, through a serial interface. Additionally, a mobile application allows a user to plan and deploy a flight 


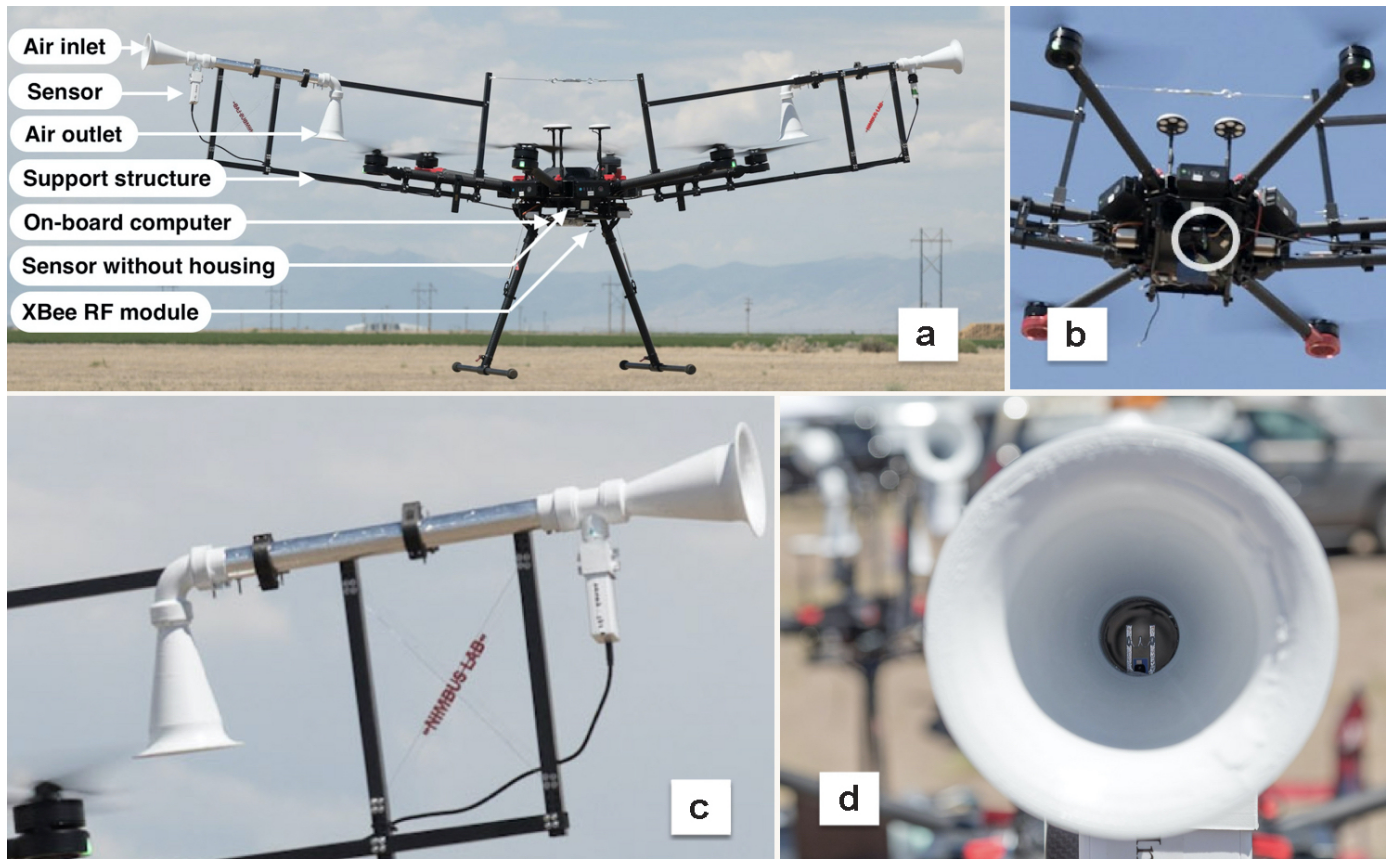

Figure 1. Images of (a) the UAS setup with the temperature and humidity sensor mounted in the aspirated and shielded sensor housing and in a traditional configuration. (b) Close-up of the traditionally mounted sensor under the UAS without the sensor housing (inside the white circle), (c) close-up of the sensor housing with the sensor mounted, and (d) close-up of the sensor probe mounted inside our sensor housing. The outlet of the sensor housing is placed on top of the propeller, and the inlet is pointing outward. High-speed air in the sensor housing is drawn passively by exploiting the pressure deficit created by the propeller of the UAS.

trajectory, and the remote controller allows intervention from the user at any point.

\subsection{Sensors}

Table 1 describes the specifications of the temperature and humidity (TH) sensors used for the dataset. Every UAS flight used one iMet XQ2 from InterMet Systems (Grand Rapids, MI, USA) as the primary TH sensor. The XQ2 is a selfcontained sensor package designed for UASs to measure atmospheric pressure, temperature, and relative humidity. It is also equipped with a built-in GPS and an internal data logger along with a rechargeable battery. A serial interface provides access to the logs or real-time observations produced by the sensor at $1 \mathrm{~Hz}$. The internal data logger was only used as backup and is not part of this dataset. Data included in the dataset were collected through the data acquisition (DAQ) system using the serial interface. Some UAS flights featured an older version of this sensor, called iMet XQ1, as the secondary backup sensor.

Some flights also used a nimbus-pth as the secondary sensor, which is a sensor package unit we designed and built for pressure, temperature, and humidity sensors. Several nimbus-pth's can be chained as nodes for data collection. In some data files, two of these nodes might be present. In such cases, one of them was aspirated inside our sensor housing, and the other one sat directly underneath the UAS in a traditional non-aspirated configuration. In the data files, the first two sensors were shielded and aspirated inside the housing, and the third sensor (when available) was in a traditional non-aspirated configuration.

\subsection{Sensor housing}

The sensor housing is designed to meet or exceed sensor placement requirements, such as consistent aspiration for the sensors and shielding from solar radiation and other indirect heat sources. The housing draws air passively by exploiting the pressure differential between the region just above a propeller and the region just beyond the rotor wash. The airflow through the housing is always maintained as long as the propellers are spinning and provides a consistent aspiration for the sensors (Islam et al., 2019). The inlet and outlet of the housing are shaped like a cone to provide high-speed airflow across the housing tube with a small pressure difference between the two ends. Additional design considerations are made to ensure that the flow is consistent and provide airflow $\geq 5 \mathrm{~m} \mathrm{~s}^{-1}$ across the sensors even at the lowest propeller speeds.

Sensors are placed inside the tube structure as shown in panels (c) and (d) of Fig. 1. The entire sensor housing is painted with reflective white paint, and tubes are wrapped with aluminum foil tape. This results in excellent rejection of solar heating and avoids unpredictable radiation heating 
Table 1. The key manufacturer's specifications for the sensors used in different experiments: the unavailable fields are left blank. Data sheets for each sensor package are available at iMet XQ2 (InterMet Systems, 2021b), iMet XQ1 (InterMet Systems, 2021a), and nimbuspth (Digikey, 2021; Mouser, 2021)

\begin{tabular}{|c|c|c|c|c|}
\hline & & $\begin{array}{l}\text { XQ2 } \\
\text { (iMet XQ2) }\end{array}$ & $\begin{array}{l}\text { XQ1 } \\
\text { (iMet XQ1) }\end{array}$ & $\begin{array}{l}\text { nimbus-pth } \\
\text { (custom-built) }\end{array}$ \\
\hline \multirow{5}{*}{ Temperature } & Type & Bead thermistor & Bead thermistor & Bead thermistor \\
\hline & Range & -90 to $50^{\circ} \mathrm{C}$ & -95 to $50^{\circ} \mathrm{C}$ & -40 to $100^{\circ} \mathrm{C}$ \\
\hline & Response time & $1 \mathrm{~s} @ 5 \mathrm{~ms}^{-1}$ & $2 \mathrm{~s}$ & \\
\hline & Resolution & $0.01^{\circ} \mathrm{C}$ & $0.01^{\circ} \mathrm{C}$ & $0.01^{\circ} \mathrm{C}$ \\
\hline & Accuracy & $\pm 0.3^{\circ} \mathrm{C}$ & $\pm 0.3^{\circ} \mathrm{C}$ & \\
\hline \multirow{7}{*}{ Humidity } & Type & Capacitive & Capacitive & Capacitive \\
\hline & Range & $0 \%-100 \% \mathrm{RH}$ & $0 \%-100 \% \mathrm{RH}$ & $0 \%-100 \% \mathrm{RH}$ \\
\hline & & @ $25^{\circ} \mathrm{C}, 0.6 \mathrm{~s}$ & $5 \mathrm{~s} @ 1 \mathrm{~ms}^{-1}$ velocity & $8 \mathrm{~s}$ \\
\hline & Response time & @ $5^{\circ} \mathrm{C}, 5.2 \mathrm{~s}$ & & \\
\hline & & $@-10^{\circ} \mathrm{C}, 10.9 \mathrm{~s}$ & & \\
\hline & Resolution & $0.1 \% \mathrm{RH}$ & $0.7 \% \mathrm{RH}$ & $0.01 \% \mathrm{RH}$ \\
\hline & Accuracy & $\pm 5 \% \mathrm{RH}$ & $\pm 5 \% \mathrm{RH}$ & $\pm 2 \% \mathrm{RH}$ \\
\hline
\end{tabular}

bias. Such placement of sensors provides solar shielding and shielding from other artificial heat sources such as motor or battery waste heat. Since the entire housing is placed outside the body of the UAS, it creates further isolation from the artificial heat sources in the UAS. Additionally, since the aspirating airspeed is very high (Islam et al., 2019), it reduces the error from all these sources even further (Anderson and Baumgartner, 1998).

The housing is also designed to be modular, printed entirely using a 3D printer, and has an easy screw-in assembly. The impact of the housing on the UAS's stability and flight time is minimal. Further details and the full schematic of the housing and the evaluation can be found in our previous work (Islam et al., 2019).

\subsection{Data acquisition}

Data were collected using a data acquisition (DAQ) system comprised of an Odroid-XU4 (Hardkernel, 2021), a compact single-board computer that runs a Linux operating system. Odroid runs the robot operating system (ROS) (Quigley et al., 2009) that communicates with the serial devices through its USB ports. The ROS facilitates the collection of many different sensor data independently at their own output frequency, recording the timestamp for when data were generated and when they are received by the ROS. The ROS interfaces the collection of all available devices even in the case of a single device failure. Synchronization of the data can be done either at runtime or in post-processing. In our case, it was done in post-processing using MATLAB.

The communication with the DJI flight controller was implemented using the ROS interface of DJI Onboard SDK (DJI, 2021c) available to developers. This allowed the recording of all the telemetry data from the flight controller, along with high-quality positioning information. The GPS data from the iMet XQ2 and iMet XQ1 sensors were discarded as the positioning information from the flight controller was found to be of better quality.

The Odroid was connected with a ground computer using wireless $2.4 \mathrm{GHz}$ XBee radios for the operation of DAQ, debugging, and periodic checks on the data when the UAS finished a flight. The data collected by the DAQ were retrieved to the ground computer for archiving at the end of each day using an ethernet connection.

Temperature and humidity sensors were connected over serial with the ROS to send periodic updates of the observations. The UAS's autopilot also interfaced with ROS to provide updates of position, velocity, altitude, attitude, etc., which were also recorded to spatially and temporally synchronize the observation.

\subsection{UAS sensor mounting configuration and payload}

As mentioned in Sect. 2.2, the primary sensor was the iMet XQ2, and its data were recorded in the dataset with a header underscore _1 (e.g., Temperature_1, Humidity_1, Pressure_1). Other sensor data headers were followed with _2 and _3 when available. Sensor_1 and sensor_2 were shielded inside the sensor housing; however, sensor_3 was placed under the UAS in a traditional configuration without aspiration. The placement of the sensors inside the housing and sensors without the housing are marked in Fig. 1 for reference. Specific placements of the sensors on the UAS used in the data collection are described below.

\subsubsection{UAS platform M600P1}

One XQ2 (sensor_1) was placed inside the left sensor housing, and one XQ1 (sensor_2) was on an identical right sensor housing. This placement location for the left housing is 
highlighted in panel (a) of Fig. 1. The alternative setup used in some experiments replaced XQ1 with nimbus-pth (sensor_2) inside the right sensor housing (sensor names are also listed in metadata as a data source). If nimbus-pth is included in measurements, it was placed under the body of the UAS without any housing structure, as highlighted in panel (a) and panel (b) of Fig. 1.

\subsubsection{UAS platform M600P2}

One XQ2 (sensor_1) was mounted inside the left sensor housing, one nimbus-pth (sensor_2) was mounted inside the right sensor housing, and an additional nimbus-pth (sensor_3) was placed under the body of the UAS without a housing. This form of sensor placement facilitates an evaluation between the sensor placed inside the housing versus under the body of the UAS without housing. It also allows comparison of the sensors mounted on the opposite ends of the UAS. Having secondary sensors also provides a fail-safe when the primary sensors fail, such as the case of XQ2 humidity sensors on 17 July 2018 data.

The UAS's total payload during the experiments was approximately $1.8 \mathrm{~kg}$. Two sensor housings with their support structure and sensor were approximately $720 \mathrm{~g}$ each; the onboard computer was $140 \mathrm{~g}$; and miscellaneous cables, screws, etc. were approximately $200 \mathrm{~g}$. UAS flight endurance was 20-25 min with the payload.

\section{Flight locations and strategies}

\subsection{Flight locations}

During the LAPSE-RATE field campaign, measurement objectives for each day were determined based on the weather forecast, site availability, and available team resources. Many designated locations of San Luis Valley of Colorado, USA, were planned beforehand as atmospheric sampling sites depending on atmospheric phenomena of interest. The planning of locations, atmospheric phenomenon to be observed for the day, and assignment of teams are described in de Boer et al. (2020a). We conducted flights in locations designated as Golf, Gamma, Leach, India, and Charlie between 14-19 July as part of the LAPSE-RATE flight campaign (de Boer et al., 2020b) as well as individual research objectives. GPS coordinates of these locations are provided in Table 2 and illustrated in a terrain map in Fig. 2. Inset (b) of Fig. 2 shows the flight locations of UNL UASs in the context of all the LAPSE-RATE flight campaign locations of interest where all the teams were operating based on the measurement objective of the day.

\subsection{Flight strategies}

Flight strategies for each day were dictated by atmospheric phenomena being measured. The teams participating in the
Table 2. Latitude, longitude, and mean sea level (m.s.1.) altitude of operation locations in World Geodetic System 84 (WGS 84) decimal degrees.

\begin{tabular}{lrrr}
\hline Location & Latitude & Longitude & Altitude (m.s.1.) \\
\hline Golf & 37.626963 & -105.820028 & $2298 \mathrm{~m}$ \\
Gamma & 37.893536 & -105.716137 & $2329 \mathrm{~m}$ \\
Leach airfield & 37.784560 & -106.044552 & $2316 \mathrm{~m}$ \\
India & 38.051294 & -106.102885 & $2332 \mathrm{~m}$ \\
Charlie & 38.052690 & -106.087414 & $2329 \mathrm{~m}$ \\
\hline
\end{tabular}

LAPSE-RATE campaign coordinated flights across the San Luis Valley according to the atmospheric phenomena of interest for the day and the atmospheric variability expected at different sampling locations. Measurement objectives of LAPSE-RATE in which the UNL participated in data collection are calibration flight (CLF), boundary layer transition (BLT), convection initiation (CI), cold air drainage flow (CDF). Table 3 shows the locations of UASs deployed by the UNL by date, time, and the corresponding mission objectives.

All the flights were conducted under the command of one remote pilot in command (PIC) with a "Federal Aviation Administration (FAA) part 107" license in accordance with the FAA's rule. All the flights included in the dataset were conducted using preprogrammed missions in the DJI Ground Station (GS) Pro app (DJI, 2021a) by the remote PIC, with very few exceptions of manual flights. Occasionally the remote PIC took control over segments of flights from the automatic mission control of the app when deemed safer by the PIC, e.g., when passing through a turbulent layer of atmosphere. Although visual observers (VOs) were not required by the FAA, two VOs were present at each flight location for greater situational awareness and safety during each flight. VOs were monitoring the UAS's movement, took handwritten notes about flight events and weather, and scanned the surrounding area for manned and unmanned flights.

All the flights were legally conducted under an FAA Certificate of Authorization (COA) for altitudes up to 914.4 m a.g.l. when Notices to Airmen (NOTAMs) were active in the blue area marked in inset (a) of Fig. 2. For all our flights, however, we were limited to flying up to a $500 \mathrm{~m}$ maximum altitude due to the altitude limitation set in the firmware of the UAS. On the days when NOTAMs were not active for the COA, all the flights were conducted up to the legal flight limit of $121 \mathrm{~m}$ a.g.l. as defined in the "part 107" regulations.

\subsubsection{July 2018}

On 14 July 2018, the mission objective was to compare both of the systems against a reference point, the Mobile UAS Research Collaboratory (MURC) tower (de Boer et al., 2021), to calibrate and validate the sensor observations. MURC 


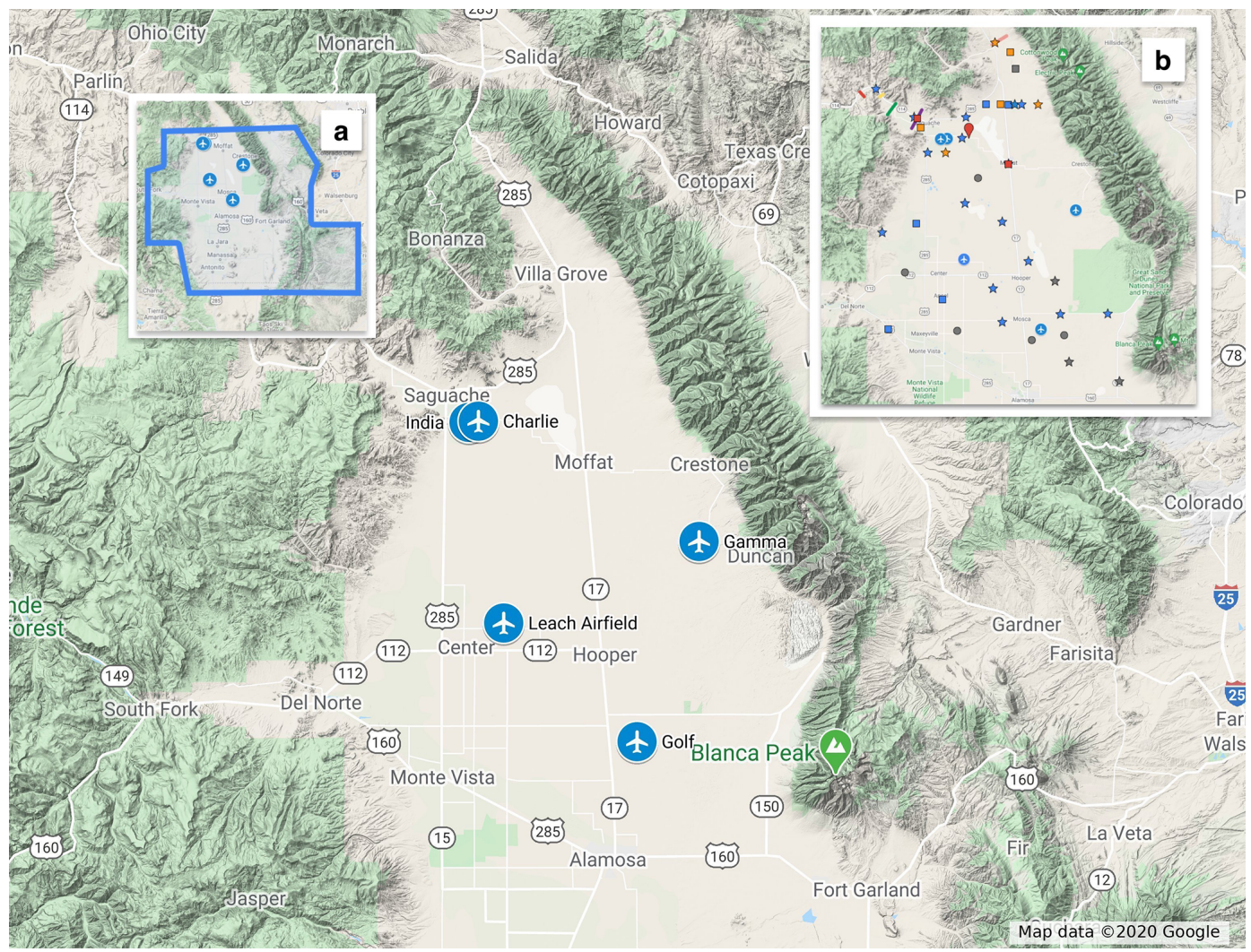

Figure 2. Flight locations of UNL UASs overlaid on the terrain map. Inset (a) shows the blue overlay area where operation of small UASs for flight altitudes up to $914.4 \mathrm{~m}$ a.g.l. was authorized by the Federal Aviation Authority (FAA) Certificate of Authorization (COA) between 13-22 July. Inset (b) shows the spatial distribution of flight locations used by the UNL and all other teams participating in the LAPSE-RATE campaign for various missions between 14-19 July 2018. Map data @ Google Maps 2020.

Table 3. UAS locations and mission objectives for the day. Mission objectives are calibration flight (CLF), boundary layer transition (BLT), convection initiation (CI), cold air drainage flow (CDF).

\begin{tabular}{|c|c|c|c|c|c|c|c|c|}
\hline \multirow[b]{2}{*}{ Date and time } & \multirow[b]{2}{*}{ Objective } & \multirow[b]{2}{*}{$\begin{array}{l}\text { No. of } \\
\text { flights }\end{array}$} & \multirow[b]{2}{*}{$\begin{array}{l}\text { Maximum } \\
\text { altitude }\end{array}$} & \multicolumn{4}{|c|}{ Location } & \multirow[b]{2}{*}{ Charlie } \\
\hline & & & & Golf & Gamma & Leach & India & \\
\hline 14 July 2018 (17:17-17:33 MDT) & CLF & 2 & $120 \mathrm{~m}$ & & & M600P1 \& M600P2 & & \\
\hline 15 July 2018 (09:00-15:15 MDT) & CI & 19 & $500 \mathrm{~m}$ & M600P1 & M600P2 & & & \\
\hline 16 July 2018 (08:00-14:30 MDT) & $\mathrm{CI}$ & 47 & $120 \mathrm{~m}$ & M600P1 & M600P2 & & & \\
\hline 17 July 2019 (07:00-09:00 MDT) & BLT & 18 & $100 \mathrm{~m}$ & & & M600P1 \& M600P2 & & \\
\hline 18 July 2019 (07:00-14:30 MDT) & CI & 43 & $120 \mathrm{~m}$ & M600P1 & M600P2 & & & \\
\hline 19 July 2019 (05:30-11:00 MDT) & $\mathrm{CDF}$ & 43 & $500 \mathrm{~m}$ & & & & M600P1 & M600P2 \\
\hline
\end{tabular}

tower instrumentations were set to $15.2 \mathrm{~m}$ a.g.l. The University of Nebraska-Lincoln (UNL) Mobile Mesonet was also collecting data about $2 \mathrm{~m}$ a.g.l. for surface-level observations. Additionally, periodic radiosonde launches were conducted by the National Severe Storms Laboratory (NSSL). Figure 3 shows an overview of the spatial distribution of the MURC tower, UAS platforms, and UNL Mobile Mesonet. Details about the MURC tower's instrumentation, deploy- ment strategies, and data processing can be obtained from (de Boer et al., 2021).

One flight for each system was conducted, where the UAS ascended to the height of the MURC tower $(15.2 \mathrm{~m})$ and hovered for $10 \mathrm{~min}$. After that, the UAS ascended to $120 \mathrm{~m}$ at $1 \mathrm{~m} \mathrm{~s}^{-1}$, hovered for $30 \mathrm{~s}$, and descended at the same speed to land. This mission was performed in collaboration with all participating teams at the LAPSE-RATE campaign to provide measurement intercomparison between platforms from 


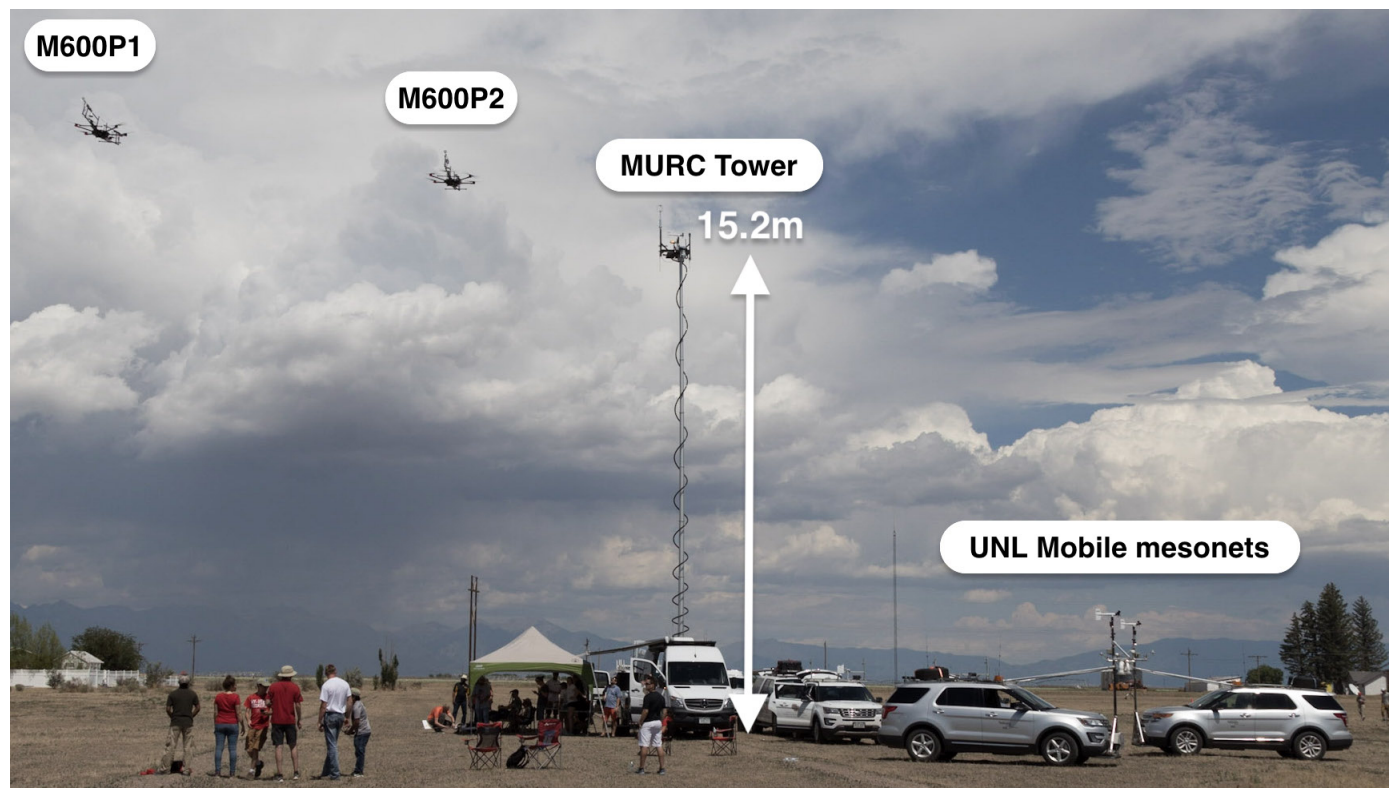

Figure 3. Coordinated data collection of the UNL UAS platforms and UNL Mobile Mesonets next to the MURC tower. UAS platforms were hovering at $15.2 \mathrm{~m}$ a.g.l. (the same altitude as MURC tower instrumentation).

all teams (Barbieri et al., 2019). The data are available for the MURC tower (de Boer et al., 2021), UNL Mobile Mesonet (de Boer et al., 2021), radiosonde (Bell et al., 2021), and all other participating teams on 14-15 July 2018 in the Zenodo community for LAPSE-RATE at the LAPSE-RATE Data Repository (2021).

\subsubsection{July 2018}

On 15 July 2018, the mission objective of the day was convection initiation $(\mathrm{CI})$. Vertical profiling flights were conducted up to $500 \mathrm{~m}$ altitude at $1 \mathrm{~m} \mathrm{~s}^{-1}$ ascent and descent speed at the Golf and Gamma locations. Flights were planned to be at every $30 \mathrm{~min}$ to allow recharge of the UAS batteries while cycling through multiple sets of batteries.

At the Golf location, 10 flights were conducted between 08:59-15:14 MDT (local time). The weather was slightly cloudy in the morning and clear throughout the rest of the day. Very windy conditions existed for the last few flights.

At the Gamma location, nine flights were conducted between 09:02-03:15 MDT (local time). Two out of the nine data files could not be recovered due to an error in the onboard logging computer and a sensor issue. The weather was clear and windy in the morning and slightly cloudy for the last half of the flights.

\subsubsection{July 2018}

On 16 July 2018, the scheduled mission objective was also CI, with flights at the same locations as the previous day. Flights were limited to $120 \mathrm{~m}$ altitude at $1.5 \mathrm{~m} \mathrm{~s}^{-1}$ ascent and descent speed due to Notice to Airmen (NOTAM) not being active for the day. Due to reduced altitude, more flights could be conducted with available batteries. As such, flights were conducted every $15 \mathrm{~min}$.

We performed 26 flights at Golf between 08:0614:34 MDT (local time). The first two flights of the morning consisted of two consecutive profiles, but it was draining the battery a lot faster than our recharging capacity. We then switched to one profile every $15 \mathrm{~min}$ to reserve enough battery in each flight to maintain a consistent interval between profiles. The weather started slightly cloudy and then remained clear throughout the day.

At Gamma, 21 flights were conducted between 09:0214:05 MDT (local time). All the profiles collected at this location are single profiles. The weather was clear throughout the day, with partly cloudy conditions persisting during the last few flights.

\subsubsection{July 2018}

On 17 July 2018, the scheduled missions were for boundary layer transition (BLT). The experiments were geared towards validation of the sensor housing by the detection of the inversion layer. We conducted the experiments in the early morning in an inversion, before sunrise, to identify if the sensor housing introduces measurement error due to the upwash or downwash of the UAS. This effect is more easily detected in stable versus well-mixed conditions since air molecules from a stable air mass will maintain the temperature of the layer even when air is pushed up or down. Thus if we can verify that the sensor housing detects inversion at the same level as 
a standard measurement (such as radiosonde), we know the readings are not affected by upwash or downwash.

We conducted simultaneous flights for both UASs with six vertical profiles and three horizontal profiles at various UAS movement speeds between 07:00-08:48 MDT (local time). The NSSL launched coordinated radiosonde balloons at regular intervals at the same location to be used as the ground truth measurement for the UAS's data. UNL Mobile Mesonets collected measurements at $2 \mathrm{~m}$ a.g.l. for surfacelevel observations during the entire duration of the experiments. The sky remained cloudy throughout all the flights.

\subsubsection{July 2018}

On 18 July 2018, the scheduled mission was for CI. Flights were conducted up to $500 \mathrm{~m}$ altitude at $1.5 \mathrm{~m} \mathrm{~s}^{-1}$ ascent and descent speed at both Golf and Gamma locations. Flights were generally conducted every $30 \mathrm{~min}$.

At the Golf location, a total of 27 flights were performed between 07:08-14:20 MDT (local time). The first 17 flights were in support of the LAPSE-RATE campaign objective. At the conclusion of the day, 10 additional $150 \mathrm{~m}$ altitude flights were performed at various ascent and descent speeds to study the effect of UAS movement speed on temperature and humidity observations.

At the Gamma location, 16 profile flights were conducted between 07:07-13:12 MDT (local time). At both locations, some flights were performed up to an altitude of $300 \mathrm{~m}$, while others were performed at $500 \mathrm{~m}$.

At both locations, the sky was clear for the first half of the flights and partly cloudy for the second half.

\subsubsection{July 2018}

On 19 July 2018, the mission objective was cold drainage flow. UASs were placed at the Charlie and India locations for this mission. Flights were performed starting before sunrise at $1.5 \mathrm{~m} \mathrm{~s}^{-1}$ ascent and descent speed. Flights were scheduled for every $15 \mathrm{~min}$. Strobe lights, as per FAA regulations, were used for flights during twilight.

At the India location, 23 flights were conducted between 05:34-11:08 MDT (local time). Maximum flight altitudes were up to $300 \mathrm{~m}$ a.g.l. for 7 flights, $350 \mathrm{~m}$ a.g.l. for 15 flights, and $500 \mathrm{~m}$ a.g.1. for 1 flight.

At the Charlie location, 21 flights were performed between 5:50-11:10 MDT (local time). Maximum flight altitudes were up to $300 \mathrm{~m}$ a.g.l. for 10 flights, $350 \mathrm{~m}$ a.g.l. for 9 flights, and $500 \mathrm{~m}$ a.g.l. for 1 flight.

At both locations, the sky was cloudy before sunrise but clear afterward.

\section{Data processing and quality control}

Data are recorded from individual sensors and the UAS flight controller as they arrive at the DAQ, as described earlier. The recorded data are then processed in MATLAB to synchronize using the zero-order hold $(\mathrm{ZOH})$ method to create a single output file. We used a discrete sample time of $1 \mathrm{~s}$ for zeroorder hold to match the output rate of primary sensors. In the $\mathrm{ZOH}$ method, the sample value is held constant for one sampling period; i.e., when temperature data are recorded from temperature sensors, the last known value of altitude from GPS data is recorded without any interpolation. Since the GPS data are recorded at a higher frequency from the flight controller, they are assumed to be close and within GPS's uncertainty in measurement. Invalid or missing data are replaced with -9999.9 wherever the sensor data are unavailable to the DAQ. No other processing was done on the data, such as sensor response correction, bias correction, etc.

We note that the humidity observations of the primary sensor on some flights for 17 July 2018 were saturated at $100 \%$ in one of the UASs (M600P1), and the corresponding data are not usable. Secondary-sensor measurements should be used to replace these data. Also, humidity readings from nimbuspth have sensitivity issues; although it displays a similar trend as the other sensors, it does not capture the whole range of observation and will need further calibration.

Files were formatted in NetCDF format, with common variable names and metadata added, to be consistent with all the entities collecting data for the LAPSE-RATE field campaign. A detailed explanation of the naming conventions and metadata that were requested can be obtained from de Boer et al. (2020b). An example file name produced by UAS platforms M600P1 and M600P2 for the data collected starting at 23:16:33 UTC on 14 July 2018 would be UNL.MR6P1.a0.20180714.231633.nc and UNL.MR6P2.a0.20180714.231633.nc, respectively. Here,

- "UNL" is the identifier for the data collecting institution, UNL;

_ "MR6P1" and "MR6P2" are the platform identifiers for M600P1 and M600P2, respectively;

- "a0" indicates raw data converted to NetCDF;

- "20180714" is the UTC file date in yyyymmdd (year, month, day) format;

- "231633" is the UTC file start time in hhmmss (hours, minutes, seconds) format;

_ "nc" is the NetCDF file extension.

All the files also contain metadata for each variable with an explanation of physical measurement units, time synchronization method, and sensors used for the measurement. File naming conventions and explanations are also described in the read-me file of the Zenodo data repository. 


\section{Special topics of interest}

The following are special topics of interest that can be studied from the dataset. Our analysis that focused on these topics can be found in our previous work (Islam et al., 2019).

\subsection{Calibration}

Data from 14 July 2018 can be used with MURC data available at the Zenodo data repository (de Boer et al., 2021) to obtain a calibration. Correction of bias in sensor readings during post-processing requires calibration against a known reliable measurement. It also serves as additional validation for the sensor platforms and their collected data. It also facilitates the comparison of data collected by different platforms by providing a "ground truth" to compare against. Our previous paper (Islam et al., 2019) discusses the deviation of our observations with MURC data over a period of $10 \mathrm{~min}$. Other work (Barbieri et al., 2019) compares all the different platforms participating in the LAPSE-RATE campaign along with ours against MURC tower data.

\subsection{Effect of ascent and descent speed}

Ten flights from the M600P1 platform on 18 July 2020 starting at 20:21 UTC (local time 14:21 MDT) can be used to study the effect of ascent and descent speed on the sensor readings. Flights were conducted up to $150 \mathrm{~m}$ altitude, with speeds ranging from $1-5 \mathrm{~m} \mathrm{~s}^{-1}$ ascent speed and $1-3 \mathrm{~m} \mathrm{~s}^{-1}$ descent speed. While it is desirable to move at a faster speed to optimize battery power usage to profile at greater altitudes, it may contribute to the effective sensor response time. Characterizing the sensor response at the different ascent and descent speeds would allow for the corresponding correction in the post-processing of the data. Our analysis of these data can also be found in our paper (Islam et al., 2019).

\subsection{Detection of inversion}

The first six flights from each platform can be used from 17 July 2020 to study the sensor performance within an inversion layer. The speed of flight through the inversion layer ranged from $0.5-5 \mathrm{~m} \mathrm{~s}^{-1}$ for ascent and $0.5-3 \mathrm{~m} \mathrm{~s}^{-1}$ for descent. The flights were coordinated with radiosonde launches from the National Severe Storms Laboratory (NSSL) to compare the UAS profiles against the radiosonde profiles. The University of Nebraska-Lincoln (UNL) Mobile Mesonet was also collecting data at the ground for surface-level observations. The dataset for radiosonde observations by the NSSL (Bell et al., 2021) and surface observations by the UNL Mobile Mesonet (de Boer et al., 2021) is uploaded to Zenodo for intercomparison. The ability to detect the inversion at the correct altitude by the UAS sensor proves that the UAS is collecting the observations at the sensor level rather than from the upwash or downwash of the UAS. Additionally, detection of inversion provides confidence in the quality of the data from the sensor housing in both ascent and descent. Different ascent and descent speeds are used to identify the maximum speed that can be used while still acquiring quality data. Characterization of the sensor in the inversion layer provides a means for correction of observation level in case an offset is detected in the inversion layer when compared to a radiosonde. These data could also be used for comparison to the theoretical work for ascent and descent rate of sensing platforms (Houston and Keeler, 2020).

\subsection{Effect of body-relative wind direction and horizontal transect}

Data are available to study sensor performance during horizontal transect with different orientations relative to the wind. The last three flights from each platform on 17 July 2020 can be used for this purpose. Horizontal flight speed ranged from $2-10 \mathrm{~m} \mathrm{~s}^{-1}$. These data can also be compared with radiosonde profile (Bell et al., 2021) and surface observations (de Boer et al., 2021) similar to Sect. 5.3. The horizontal flights at different speeds against various orientations of wind provide additional characterizations for the quality of sensor data at various atmospheric wind conditions. Different horizontal flight speed simulates different incident wind speed at the sensor housing inlet and its effect on the observations. At the same time, the orientation of the sensor housing simulates incident wind at different orientations and its effects on the sensor observations. The orientation characterization is particularly important as waste heat from the UAS can be carried into the sensor housing in an unfavorable wind orientation. Any bias that may appear in these tests would need to be considered in the profiling flight plan to optimize the orientation of the sensor housing inlet relative to the wind to collect quality data and make appropriate corrections in the post-processing. Our analysis of these data can also be found in our previous work (Islam et al., 2019). Although traditionally a multirotor UAS is used for vertical profiling, our data show reliable data collection is also possible for horizontal profiles and transects using our sensor housing.

\section{Examples of collected profiles}

Figure 4 shows examples of temperature and humidity profiles collected using the M600P1 platform's primary sensor. The top two panels illustrate a $500 \mathrm{~m}$ profile taken through a well-mixed atmosphere. The bottom two panels in Fig. 4 are an example of a profile taken before sunrise through a nocturnal inversion. Although the housing is designed to address ascent-descent differences, the sensor and the housing have an inherent response time that cannot be eliminated. The utility of the presented sensor housing is to keep the effective response time consistent irrespective of the atmospheric condition or orientation of the sensor relative to the wind or sun. The data presented in the figures are not filtered or cor- 

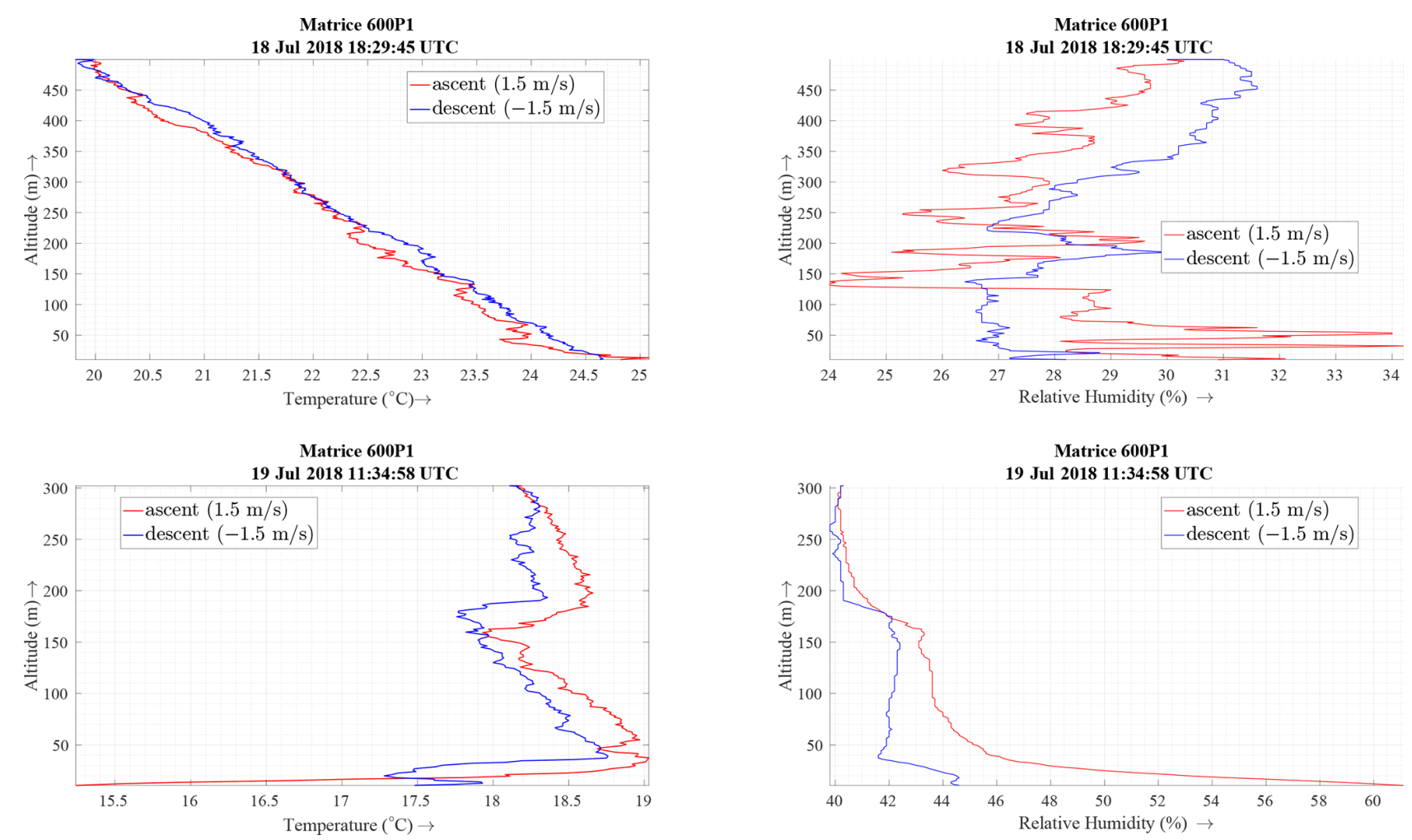

Figure 4. Examples of two vertical profiles collected using UAS: M600P1. The top row corresponds to a $500 \mathrm{~m}$ profile in a well-mixed atmosphere; the bottom row corresponds to a $300 \mathrm{~m}$ profile during a nocturnal inversion before sunrise. The figures show raw data as they were collected, thus showing a difference in ascent and descent measurement as expected due to sensor response time. Humidity sensor response time is slower than temperature sensor (at the temperatures when flights were conducted), and response time changes with temperature (see Table 1). As such, the difference between ascent and descent is much larger for humidity readings, with additional variability introduced by changing sensor response time. Even without correction, it should be noted that the ascent and descent readings are within the bounds of sensor uncertainty $\left( \pm 0.3{ }^{\circ} \mathrm{C}\right.$ and $\pm 5 \% \mathrm{RH}$ for temperature and humidity sensors, respectively) and show how effective sensor housing is in collecting quality data.

rected for effective sensor response time. The raw data without any sensor response correction are presented to show the impact of a proper sensor housing on the observations collected by temperature and humidity sensors. This response lag causes a deviation in ascent and descent reading as is expected. Ascent-descent deviation for the humidity sensor is larger due to its slower response time in colder temperatures. Even without any correction, ascent and descent readings in our data were within the bounds of sensor uncertainty $\left( \pm 0.3^{\circ} \mathrm{C}\right.$ and $\pm 5 \% \mathrm{RH}$ for temperature and humidity sensors, respectively) and show how effective the sensor housing is in collecting quality data. It should be noted that correction can be done using sensor response time as listed by the manufacturer in Table 1. A rigorous correction would require the characterization of the sensor installed in the housing "as flown" (McCarthy, 1973). The data from MURC (de Boer et al., 2021) and the UNL Mobile Mesonet (de Boer et al., 2021) can be used as an additional calibration point, as discussed in Sect. 5.
Figures 5 and 6 show primary-sensor (XQ2) temperature and relative humidity profiles, respectively, for all the flights conducted between 15-19 July 2018. The profiles are plotted using an artificial horizontal axis offset for clarity. These figures serve the purpose of providing a quick glance over the entire dataset and of locating interesting flights for further study. It should be noted that all the presented data are raw data as collected by the sensors without any correction for sensor response time or bias correction.

In Fig. 5, flights conducted on 15, 16, and 18 July to investigate "convection initiation" (CI) show a well-mixed atmosphere profile for most flights, with a steady lapse rate of temperature. Data from M600P1 on 18 July at the Golf location (see Tables 2 and 3) show the presence of an inversion in the early morning flights. Also, notice that the last 10 profiles for M600P1 with varying speed produce an ascentdescent difference in various amounts due to a change in effective sensor response time. Data collected at Leach airport to investigate "boundary layer transition" (BLT) on 17 July show a strong presence of an inversion in all flights. Data 

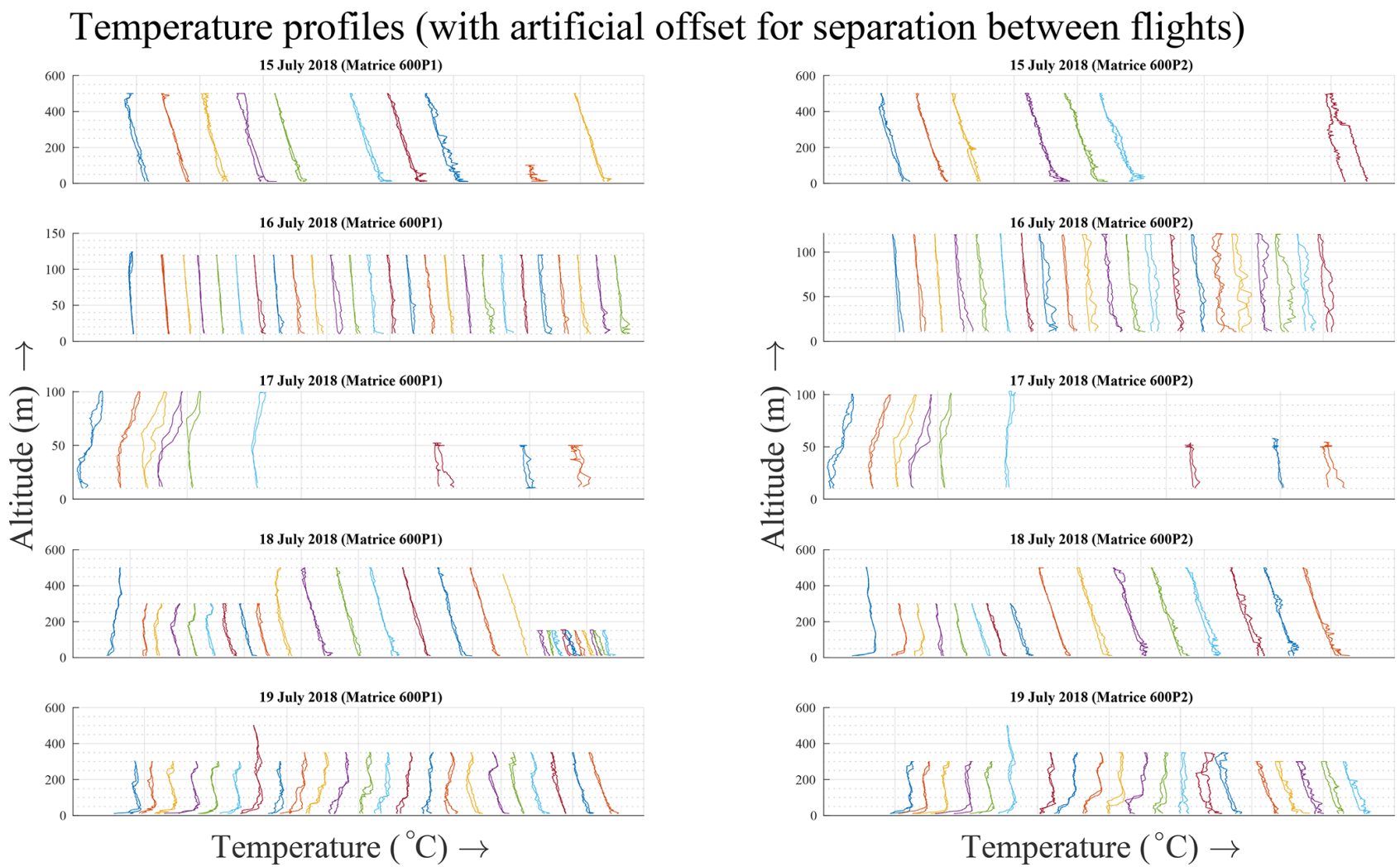

Figure 5. Temperature profiles from the primary sensor (XQ2) in all flights from 15-19 July 2018. The horizontal axis does not represent a continuous temperature scale; each profile within a day is displaced along the horizontal to avoid overlap. Order from left to right on each subplot indicates the order in which flights were conducted. Table 3 can be consulted for information about flight start times and site location for each UAS on a particular day.

from 19 July collected to investigate "cold air drainage flow" (CDF) show progression of the ABL from inversion before sunrise in the early flights to a well-mixed condition for the last few flights of the day.

In Fig. 6, flights conducted on 17 July by M600P1 show primary-humidity-sensor failure. However, data files include secondary-sensor humidity measurements that should be used for analysis instead. Since the humidity sensors have a higher sensor response time at the temperature at which we conducted most of our flights, it may show greater hysteresis than the temperature sensor. We also found that the humidity sensor would collect microdust particles as it was being flown, which could affect the accuracy of the sensors further. Another interesting feature of the humidity data presented here shows that readings are much smoother when collecting data in an inversion compared to data in a well-mixed atmosphere. Additionally, the difference between ascent and descent is much higher near ground level for most flights; this is the result of a rapid change in humidity near ground and sensor response time of humidity sensors.

\section{Data availability}

The dataset is available at Zenodo with Creative Commons License (https://doi.org/10.5281/zenodo.4306086, Islam et al., 2020).

\section{Conclusions}

As part of the LAPSE-RATE measurement campaign in July 2018 in San Luis Valley, Colorado, USA, the UNL participated in data collection in support of science missions focused on convection initiation, boundary layer transition, and cold air drainage flow. The UNL deployed two UASs in five locations for these missions. A total of 172 flights were conducted up to a maximum $500 \mathrm{~m}$ altitude above ground level (a.g.l.), resulting in an interesting and diverse dataset that can be studied individually or along with data from other teams participating in the LAPSE-RATE campaign.

Author contributions. $\mathrm{AH}$ and $\mathrm{CD}$ planned the contribution of the University of Nebraska-Lincoln contributions to LAPSE-RATE. AI designed the sensor housing and support structures. All authors contributed to data collection and analysis. AI, AS, and CD were 


\section{Relative Humidity profiles (with artificial offset for separation between flights)}
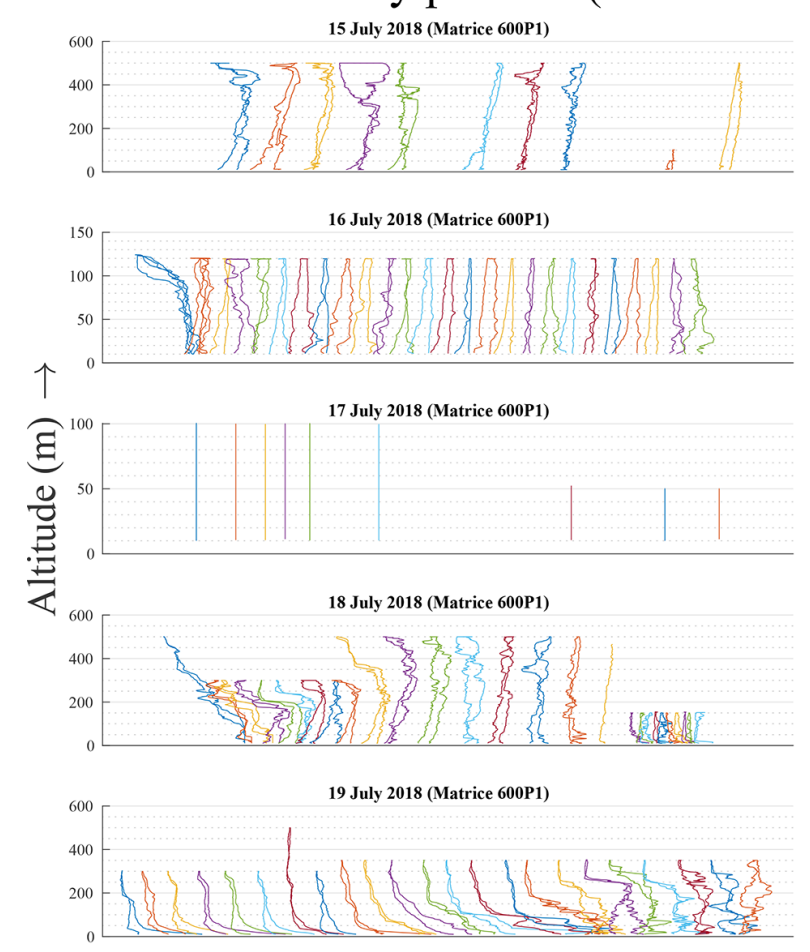

Relative Humidity $(\% \mathrm{RH}) \rightarrow$
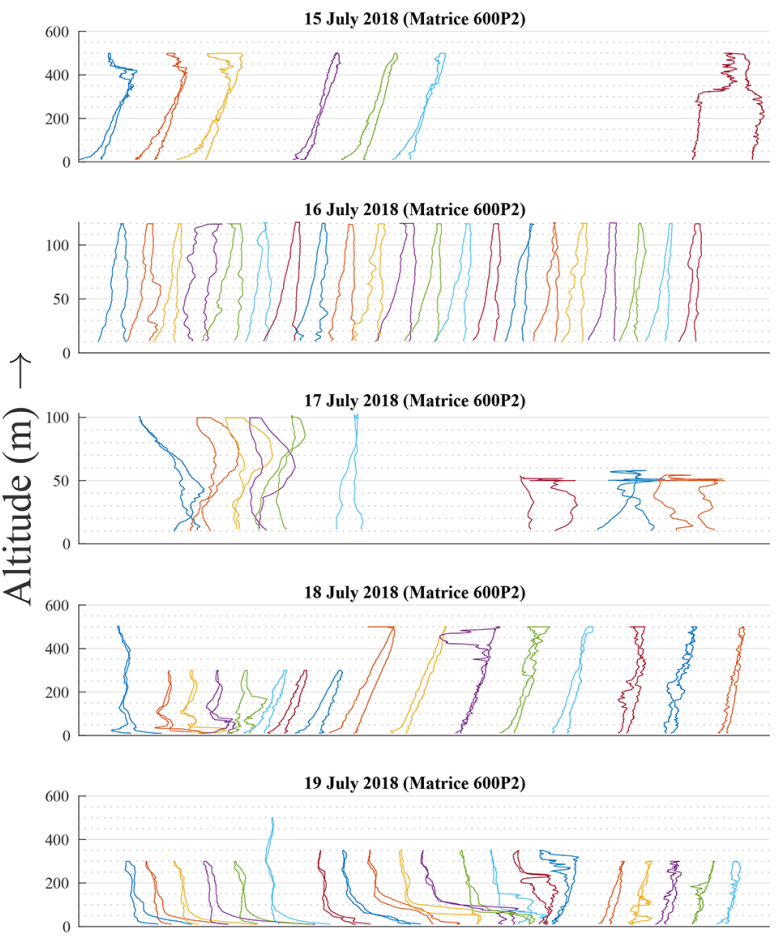

Relative Humidity $(\% \mathrm{RH}) \rightarrow$

Figure 6. Relative humidity profile from the primary sensor (XQ2) in all flights from 15-19 July 2018. The horizontal axis does not represent a continuous humidity scale; each profile within a day is displaced along the horizontal to avoid overlap. Order from left to right on each subplot indicates the order in which flights were conducted. Table 3 can be consulted for information about flight start times and site location for each UAS on a particular day.

part of the multirotor flight team. AI and AS contributed to data processing and presentation. AI constructed the manuscript. All authors contributed to manuscript edits. $\mathrm{AH}$ and $\mathrm{CD}$ acquired the funding for the paper.

Competing interests. The authors declare no competing interests. The funders had no role in the design of the study; in the collection, analyses, or interpretation of the data; in the writing of the manuscript; or in the decision to publish the results.

Disclaimer. The views, findings, conclusions, and recommendations expressed in the paper are those of the authors and do not necessarily represent the views of the funding agencies.

Special issue statement. This article is part of the special issue "Observational and model data from the 2018 Lower Atmospheric Process Studies at Elevation - a Remotely-piloted Aircraft Team Experiment (LAPSE-RATE) campaign". It is a result of the International Society for Atmospheric Research using Remotelypiloted Aircraft (ISARRA 2018) conference, Boulder, USA, 9-12 July 2018.
Acknowledgements. This work was partially supported by NSF IIA-1539070, IIS-1638099, IIS-1925052, IIS-1925368, NASA ULI-80NSSC20M0162, and USDA-NIFA 2017-67021-25924. Limited general support for LAPSE-RATE was provided by the US National Science Foundation (AGS 1807199) and the US Department of Energy (DE-SC0018985) in the form of travel support for early-career participants. Support for the planning and execution of the campaign was provided by the NOAA Physical Sciences Division and NOAA UAS program.

We thank Jason Finnegan and Amy Guo for their help with data collection during the LAPSE-RATE flight campaign. We would like to thank Sean Waugh and the National Severe Storms Laboratory for the radiosonde data. We also thank Steve Borenstein and Cory Dixon for their help with the MURC operations.

Financial support. This research has been supported by the National Science Foundation (grant nos. IIA-1539070, IIS-1638099, IIS-1925052, IIS-1925368, NASA ULI-80NSSC20M0162, and AGS 1807199); the US Department of Agriculture, National Institute of Food and Agriculture (grant no. 2017-67021-25924); and the US Department of Energy (grant no. DE-SC001898). 
Review statement. This paper was edited by Suzanne Smith and reviewed by two anonymous referees.

\section{References}

Anderson, S. P. and Baumgartner, M. F.: Radiative Heating Errors in Naturally Ventilated Air Temperature Measurements Made from Buoys, J. Atmos. Ocean. Tech., 15, 157-173, https://doi.org/10.1175/15200426(1998)015<0157:rheinv>2.0.co;2, 1998.

Barbieri, L., Kral, S., Bailey, S., Frazier, A., Jacob, J., Reuder, J., Brus, D., Chilson, P., Crick, C., Detweiler, C., Doddi, A., Elston, J., Foroutan, H., González-Rocha, J., Greene, B., Guzman, M., Houston, A., Islam, A., Kemppinen, O., Lawrence, D., Pillar-Little, E., Ross, S., Sama, M., Schmale, D., Schuyler, T., Shankar, A., Smith, S., Waugh, S., Dixon, C., Borenstein, S., and de Boer, G.: Intercomparison of Small Unmanned Aircraft System (sUAS) Measurements for Atmospheric Science during the LAPSE-RATE Campaign, Sensors, 19, 2179, https://doi.org/10.3390/s19092179, 2019.

Bell, T. M., Klein, P. M., Lundquist, J. K., and Waugh, S.: Remotesensing and radiosonde datasets collected in the San Luis Valley during the LAPSE-RATE campaign, Earth Syst. Sci. Data, 13, 1041-1051, https://doi.org/10.5194/essd-13-1041-2021, 2021.

Bonin, T., Chilson, P., Zielke, B., and Fedorovich, E.: Observations of the Early Evening Boundary-Layer Transition Using a Small Unmanned Aerial System, Bound.-Lay. Meteorol., 146, 119-132, https://doi.org/10.1007/s10546-012-9760-3, 2013.

Dabberdt, W. F., Schlatter, T. W., Carr, F. H., Joe Friday, E. W., Jorgensen, D., Koch, S., Pirone, M., Ralph, F. M., Sun, J., Welsh, P., Wilson, J. W., and Zou, X.: Multifunctional Mesoscale Observing Networks, B. Am. Meteorol. Soc., 86, 961-982, https://doi.org/10.1175/bams-86-7-961, 2005.

de Boer, G., Diehl, C., Jacob, J., Houston, A., Smith, S. W., Chilson, P., Schmale, D. G., Intrieri, J., Pinto, J., Elston, J., Brus, D., Kemppinen, O., Clark, A., Lawrence, D., Bailey, S. C. C., Sama, M. P., Frazier, A., Crick, C., Natalie, V., Pillar-Little, E., Klein, P., Waugh, S., Lundquist, J. K., Barbieri, L., Kral, S. T., Jensen, A. A., Dixon, C., Borenstein, S., Hesselius, D., Human, K., Hall, P., Argrow, B., Thornberry, T., Wright, R., and Kelly, J. T.: Development of Community, Capabilities, and Understanding through Unmanned Aircraft-Based Atmospheric Research: The LAPSE-RATE Campaign, B. Am. Meteorol. Soc., 101, E684E699, https://doi.org/10.1175/bams-d-19-0050.1, 2020a.

de Boer, G., Houston, A., Jacob, J., Chilson, P. B., Smith, S. W., Argrow, B., Lawrence, D., Elston, J., Brus, D., Kemppinen, O., Klein, P., Lundquist, J. K., Waugh, S., Bailey, S. C. C., Frazier, A., Sama, M. P., Crick, C., Schmale III, D., Pinto, J., Pillar-Little, E. A., Natalie, V., and Jensen, A.: Data generated during the 2018 LAPSE-RATE campaign: an introduction and overview, Earth Syst. Sci. Data, 12, 3357-3366, https://doi.org/10.5194/essd-123357-2020, 2020b.

de Boer, G., Waugh, S., Erwin, A., Borenstein, S., Dixon, C., Shanti, W., Houston, A., and Argrow, B.: Measurements from mobile surface vehicles during the Lower Atmospheric Profiling Studies at Elevation - a Remotely-piloted Aircraft Team Experiment (LAPSE-RATE), Earth Syst. Sci. Data, 13, 155-169, https://doi.org/10.5194/essd-13-155-2021, 2021.
Diaz, P. V. and Yoon, S.: High-Fidelity Computational Aerodynamics of Multi-Rotor Unmanned Aerial Vehicles, in: 2018 AIAA Aerospace Sciences Meeting, American Institute of Aeronautics and Astronautics, Kissimmee, Florida, USA, p. 1266, https://doi.org/10.2514/6.2018-1266, 2018.

Digikey: Nimbus-pth Temperature Sensor Datasheet, available at: https://media.digikey.com/pdf/DataSheets/LittelfusePDFs/ GP103J4F.pdf, last access: 27 April 2021.

DJI: DJI Ground Station Pro, available at: https://www.dji.com/ ground-station-pro, last access: 27 April 2021a.

DJI: DJI Matrice 600 Pro - Product Information, available at: https: //www.dji.com/matrice600-pro/info, last access: 27 April 2021b.

DJI: DJI Developer - Onboard SDK, available at: https://developer. dji.com/onboard-sdk/, last access: 27 April 2021c.

Elston, J., Argrow, B., Stachura, M., Weibel, D., Lawrence, D., and Pope, D.: Overview of Small Fixed-Wing Unmanned Aircraft for Meteorological Sampling, J. Atmos. Ocean. Tech., 32, 97-115, https://doi.org/10.1175/jtech-d-13-00236.1, 2015.

Greatwood, C., Richardson, T., Freer, J., Thomas, R., MacKenzie, A., Brownlow, R., Lowry, D., Fisher, R., and Nisbet, E.: Atmospheric Sampling on Ascension Island Using Multirotor UAVs, Sensors, 17, 1189, https://doi.org/10.3390/s17061189, 2017.

Greene, B., Segales, A., Bell, T., Pillar-Little, E., and Chilson, P.: Environmental and Sensor Integration Influences on Temperature Measurements by Rotary-Wing Unmanned Aircraft Systems, Sensors, 19, 1470, https://doi.org/10.3390/s19061470, 2019.

Greene, B. R., Segales, A. R., Waugh, S., Duthoit, S., and Chilson, P. B.: Considerations for temperature sensor placement on rotarywing unmanned aircraft systems, Atmos. Meas. Tech., 11, 55195530, https://doi.org/10.5194/amt-11-5519-2018, 2018.

Hardkernel: ODROID-XU4, available at: https://wiki.odroid.com/ odroid-xu4/odroid-xu4, last access: 27 April 2021.

Hemingway, B., Frazier, A., Elbing, B., and Jacob, J.: Vertical Sampling Scales for Atmospheric Boundary Layer Measurements from Small Unmanned Aircraft Systems (sUAS), Atmosphere, 8, 176, https://doi.org/10.3390/atmos8090176, 2017.

Hemingway, B. L., Frazier, A. E., Elbing, B. R., and Jacob, J. D.: High-Resolution Estimation and Spatial Interpolation of Temperature Structure in the Atmospheric Boundary Layer Using a Small Unmanned Aircraft System, Bound.-Lay. Meteorol., 175, 397-416, https://doi.org/10.1007/s10546-020-00512-1, 2020.

Houston, A. L. and Keeler, J. M.: The Impact of Sensor Response and Airspeed on the Representation of the Convective Boundary Layer and Airmass Boundaries by Small Unmanned Aircraft Systems, J. Atmos. Ocean. Tech., 35, 16871699, https://doi.org/10.1175/jtech-d-18-0019.1, 2018.

Houston, A. L. and Keeler, J. M.: Sounding Characteristics That Yield Significant Convective Inhibition Errors Due to Ascent Rate and Sensor Response of In Situ Profiling Systems, J. Atmos. Ocean. Tech., 37, 1163-1172, https://doi.org/10.1175/jtech-d19-0191.1, 2020.

InterMet Systems: iMet-XQ1 UAV Sensor, available at: https://www.intermetsystems.com/ee/pdf/202020_iMet-XQ_ 161005.pdf, last access: 27 April 2021a.

InterMet Systems: iMet-XQ2 UAV Sensor, available at: https://www.intermetsystems.com/ee/pdf/202021_iMet-XQ2_ 171207.pdf, last access: 27 April 2021b.

Islam, A., Houston, A. L., Shankar, A., and Detweiler, C.: Design and Evaluation of Sensor Housing for Bound- 
ary Layer Profiling Using Multirotors, Sensors, 19, 2481, https://doi.org/10.3390/s19112481, 2019.

Islam, A., Houston, A., Shankar, A., and Detweiler, C.: University of Nebraska-Lincoln Unmanned Aerial System Observations from LAPSE-RATE, Zenodo [data set], https://doi.org/10.5281/ZENODO.4306086, 2020.

Jacob, J., Chilson, P., Houston, A., and Smith, S.: Considerations for Atmospheric Measurements with Small Unmanned Aircraft Systems, Atmosphere, 9, 252, https://doi.org/10.3390/atmos9070252, 2018.

LAPSE-RATE Data Repository: Data Repository for Lower Atmospheric Profiling Studies at Elevation - a Remotely-Piloted Aircraft Team Experiment (LAPSE-RATE), available at: https: //zenodo.org/communities/lapse-rate/?page $=1 \&$ size $=20$, last access: 27 April 2021.

Lee, T., Buban, M., Dumas, E., and Baker, C.: On the Use of Rotary-Wing Aircraft to Sample Near-Surface Thermodynamic Fields: Results from Recent Field Campaigns, Sensors, 19, 10, https://doi.org/10.3390/s19010010, 2018.

Leuenberger, D., Haefele, A., Omanovic, N., Fengler, M., Martucci, G., Calpini, B., Fuhrer, O., and Rossa, A.: Improving High-Impact Numerical Weather Prediction with Lidar and Drone Observations, B. Am. Meteorol. Soc., 101, E1036-E1051, https://doi.org/10.1175/bams-d-19-0119.1, 2020.

McCarthy, J.: A Method for Correcting Airborne Temperature Data for Sensor Response Time, J. Appl. Meteorol. Clim., 12, 211-214, https://doi.org/10.1175/15200450(1973)012<0211:amfcat>2.0.co;2, 1973.

Mitchell, T., Hartman, M., Johnson, D., Allamraju, R., Jacob, J. D., and Epperson, K.: Testing and Evaluation of UTM Systems in a BVLOS Environment, in: AIAA AVIATION 2020 FORUM, American Institute of Aeronautics and Astronautics, VIRTUAL EVENT, https://doi.org/10.2514/6.2020-2888, 2020.

Mouser: Nimbus-pth Humidity Sensor Datasheet, available at: https://www.mouser.com/datasheet/2/682/Sensirion_Humidity_ Sensors_SHT3x_Datasheet_digital-971521.pdf, last access: 27 April 2021.
Nolan, P., Pinto, J., González-Rocha, J., Jensen, A., Vezzi, C., Bailey, S., de Boer, G., Diehl, C., Laurence, R., Powers, C., Foroutan, H., Ross, S., and Schmale, D.: Coordinated Unmanned Aircraft System (UAS) and Ground-Based Weather Measurements to Predict Lagrangian Coherent Structures (LCSs), Sensors, 18, 4448, https://doi.org/10.3390/s18124448, 2018.

Palomaki, R. T., Rose, N. T., van den Bossche, M., Sherman, T. J., and De Wekker, S. F. J.: Wind Estimation in the Lower Atmosphere Using Multirotor Aircraft, J. Atmos. Ocean. Tech., 34, 1183-1191, https://doi.org/10.1175/jtech-d-16-0177.1, 2017.

Prudden, S., Fisher, A., Mohamed, A., and Watkins, S.: A Flying Anemometer Quadrotor: Part 1, in: Proceedings of the International Micro Air Vehicle Conference (IMAV 2016), Beijing, China, 17-21, 2016.

Quigley, M., Conley, K., Gerkey, B., Faust, J., Foote, T., Leibs, J., Wheeler, R., and Ng, A. Y.: ROS: an open-source Robot Operating System, in: ICRA workshop on open source software, vol. 3, p. 5, Kobe, Japan, 2009.

Segales, A. R., Greene, B. R., Bell, T. M., Doyle, W., Martin, J. J., Pillar-Little, E. A., and Chilson, P. B.: The CopterSonde: an insight into the development of a smart unmanned aircraft system for atmospheric boundary layer research, Atmos. Meas. Tech., 13, 2833-2848, https://doi.org/10.5194/amt13-2833-2020, 2020.

Villa, T., Salimi, F., Morton, K., Morawska, L., and Gonzalez, F.: Development and Validation of a UAV Based System for Air Pollution Measurements, Sensors, 16, 2202, https://doi.org/10.3390/s16122202, 2016.

Yoon, S., Diaz, P. V., Boyd Jr., D. D., Chan, W. M., and Theodore, C. R.: Computational Aerodynamic Modeling of Small Quadcopter Vehicles, in: Computational Aerodynamic Modeling of Small Quadcopter Vehicles, in: American Helicopter Society (AHS) 73rd Annual Forum, p. 16, Fort Worth, Texas, USA, 2017. 